\title{
An Analysis on the Importance of Motivation and Strategy in Postgraduates English Acquisition
}

\author{
Ruizhen Feng \& Hong Chen \\ School of Foreign Languages, Jiangsu University \\ 301 Xuefu Road, Zhenjiang 212013, China \\ Tel: 86-511-8879-1205 E-mail: zf825@163.com
}

The research is financed by the Education Department of Jiangsu Province, China. (Project Code No. 03KJD630286)

\begin{abstract}
Postgraduates' English acquisition is an intriguing but complex process. A lot of factors have contributed to the outcome of a learner's acquisition, among them, motivation and strategy are playing a crucial role. Motivation is the driving force to encourage the learner to learn, while strategy being the techniques or devices for a learner to use for gaining knowledge. Since both belong to learner factors that may account for individual differences in postgraduates' English acquisition process, it is essential to discuss and analyze them for Postgraduates' English achievement.
\end{abstract}

Keywords: Postgraduates' English acquisition, Motivation and strategy, Learner factors

\section{Introduction}

\subsection{Factors affecting the outcome of postgraduates' English acquisition}

In second language acquisition, many scholars argue that in the same class setting. Some students progress rapidly while others struggle along making very slow progress. Some learners never achieve nativelike command of a second language. Researches show that different kinds of factors from various aspects influence the process of second language acquisition and make it very complex. A variety of factors and their inter-relationship are shown in table 1.

\subsection{The current research trend in second language acquisition}

Researchers of different groups emphasize different factors. In second language acquisition research, there is a tendency to move from teacher-dominated instruction to individual learner-oriented process, because learner is the key player in second language acquisition. According to the schema provided above, I would argue that the learner factors are more important than others explaining individual difference in postgraduates' English achievements. Without any doubt, postgraduates in China are in the similar social, economic, cultural and linguistic background. School resources, teaching methods and assessment measurements may determine the differences of their group English level. Besides, most families of postgraduates are almost at the same living condition and most postgraduates themselves live on campus. The influence from family is quite minimal. Among all the learner factors, unmodifiable factors play an important role, but they are something given and people can not alter. It is the modifiable factors that are significant to be explored, because both learners and instructors can adopt themselves to them if they know why and how to do it. It is true that learner's learning purposes, belief and effort are part of learner's motivation(Ellis:509),so this paper considers motivation and strategy as two key factors to account for the differences of postgraduates' English learning achievement.

\section{Motivation in Postgraduates' English acquisition}

\subsection{Two kinds of definition}

Gardener defines motivation as the combination of effort plus desire to achieve the goal of learning the language plus favorable attitudes towards learning the language. He argues that motivation refers to the directed effort individual learners make to learn the language, the effects of learners' orientation are mediated by their motivation----that is, whereas, orientation and second language learning are indirectly related; motivation and achievement are directly related.

However, Ellis(1994:523-525)claims that strength of motivation serves as a power of predictor of second language achievement, but may itself be the result of previous learning experience. He offers four hypotheses to characterize a non-theoretical view of motivation. First, motivation derives from an inherent interest in the learning task the learner is asked to perform. Second, learners who do well will persevere; those who do not do well will be discouraged and try less hard. Third, the learner brings to the learning situation a certain quantity of motivation as a given. And fourth, external influences and incentives will affect the strength of the learner's motivation. It is likely that the relationship 
between motivation and achievement is an interactive one.

\subsection{Two types of classification}

Gardner and Lambert mentioned two types of motivation, integrative motivation and instrumental motivation. A learner is said to be integratively motivated when the learner wishes to identify with another ethnolinguistic group. By way of contrast to integrative one, Gardner and Lambert introduced the concept of instrumental motivation, in which the learner is motivated to learn a second language for utilitarian purposes, such as furthering a career, improving social status or meeting an educational requirement.

Through investigating the relationship between the English proficiency and motivational orientation, some researchers believed that those students with their instrumental motivation outperformed those with integrative motivation on the test of English proficiency. Other researchers found that their subjects' achievement in foreign language was linked to both types of motivation. In my opinion, it is very difficult to determine to what extent instrumental motivation outperforms integrative motivation in graduates' English achievement. It is no doubt that graduates have both instrumental and integrative motivation in the process of their English Study. Most graduates admit that they are more instrumentally motivated than integratively motivated. Even among the instrumentally motivated graduates, their "instruments", that is, the driving forces are not the same. Postgraduates in China have already learned English for at least ten years before, most of them have strong desire to achieve the goal of learning the language, but different students have set up different goals. Still some of them do not work hard enough, some even reveal unfavorable attitudes towards learning. With passive inclination, it would certainly hamper their English achievement in the end. All these differences in learning attitudes lead to the individual differences in their English proficiency, which, to a certain extent, explain the different outcome of regular English tests. Other internal sources of motivation, such as self-confidence may be more important than other types of motivation in some contests. Motivation can also take the form of intrinsic interest in specific learning activities and, as such, may be more easily influenced by teachers than goal-directed motivation.

The discussion above indicates that postgraduates have different kinds of motivation although they are in the same class. If a teacher does not know the origin of his students' motivation, or, if a teacher does not know how to guide his students' motivation to a successful learning achievement, how can he or she help them in their English study? Therefore, it is important for teachers to positively inspire their students' motivation through short-term and long-term measures, such as establishing the aims of course, and the objectives within it, and making the aims and goals of the course clear well in advance and drawing the attention of the students to the achievement of them. Through long-term and short-term measures, teachers can stimulate the students' desire to think and attract them to complete their learning task, so as to encourage the students to be interested in both the language and the culture not only in classroom, but also in the whole process of their English learning. In other words, teachers can use different kinds of measures to positively affect not only the students' instrumental motivation, but also their integrative motivation, thus leading them to the path of successful English acquisition.

\subsection{Stimulation of postgraduates'learning motivation}

In English teaching, we find that the intensity of the students' integrative motivation and instrumental motivation is not immutable. There exist inconsistency and uncertainty. The course of learning is not in a sole form. Learning motivation, in a certain stage, maybe strengthened or lessened by outside influence, while extrinsic motivation may transform into intrinsic motivation, especially for the ones with persistency, to help the learner succeed in study. As for this variability, what role should the teacher play? The teacher encounters a confliction: how will he teach? how can he transmit his force of influence into his students to form their intrinsic motivation and to increase their learning efficiency? These questions can be discussed in four aspects.

\subsubsection{Emotional factor in teaching}

Learning process is an emotional process. It is affected by different emotional factors. The teacher and his students engage in various emotional activities in it and varied fruits of emotion are yielded. What is emotion? Its implication is wide-ranging and rather implicit. It often serves as a general definition of a series of psychological phenomena, such as feeling, inner experience, need, desire, value pursuit, and so on.

Varied emotional factors work in the course of teaching and play an important role in effectiveness of learner and teacher' classroom activities. The emotional factor in the teaching environment that affects the learning mainly is the teacher's characteristic of personality. An enthusiastic and considerate teacher can offer satisfaction to the learner's extra needs. This helps strengthen the learner's study motivation. On the other hand, a teacher's attitude towards the learner has major influence on the learner's learning. As regards emotional cramming, a teacher's physically and mentally pouring into his teaching, and being filled with affection, will help arouse the learning enthusiasm of the learners. However, if the teacher only works as a "teaching craftsman" and put no emotion into teaching, the classroom will become static to lessen the learning enthusiasm of the learners. For this reason, the teacher must place emphasis on 
emotional interaction with the learner.

\subsubsection{Re-establishment of the subject in teaching.}

The status and function of the subject among the teacher and the learner in English learning is a matter of overall importance, it is also the starting point and foothold where we make a change in teaching ideology. In the process of teaching there are two subjects: the teacher and the learner, and two forms of activities: teaching and learning, still one common object - the English language. When the subject is the learner, the object as cognition is the English language, the symbolic system and its function. When the subject is the teacher, the English language as the object of cognition is not the symbolic system but an abstract law related to the language that is the law of how to learn the language.

Once the new view is established, the teacher becomes an organizer and director of teacher rather than a sole old-styled transmitter of knowledge. He will organize and direct every learning activity on base of various linguistic features and different learner groups. Actually a foreign language is mastered by learning, not by teaching. In this sense, monitoring "learning" means catching of this point. The effect of English learning depends, to large extent, upon the learner's subjective initiative and degree of participation. For that reason, the teacher should offer in class "open" questions rather than "close"questions. This method makes the teacher naturally prolong the waiting time so that more time is left for the learners to output. Activities in groups or in pairs can create more natural classroom air, which helps enhance the learners' output. If the learner participates in the classroom interaction, they will straight obtain chances of learning and mastering the language they are also involved in scheduling their own learning. All this will make them more active and more responsible. Sequentially, the strong and significant learning motivation is formed to cultivate their potential faculty, which lays a solid foundation to enhance the teaching effect and achieve the expected goal.

\subsubsection{Supplying information feedback to enhance the short-term motivation}

Behavioristic psychologists first perceived the colossal influence of feedback exerted on motivation. Weinstein (1989) once explicitly pointed out that the form and amount that were supplied by the teacher had a direct influence on the learner's learning motivation, self-awareness and sense of achievement in study, which, furthermore, influenced the learners' learning effect. In practical teaching, feedback indicates information on accomplishment of a learning task in order to improve and raise the learners' achievement. With the help of related information obtained from the teacher's feedback, the learner keep abreast of the result of his learning motivation and level of his learning behavior for greater progress in study.

\subsubsection{Proposition of new goals for enhancing long-term motivation}

English must not be treated as a sole or isolated course to learn. A postgraduate should probe for as much as possible various knowledge related to language learning by employing varied means and accesses. In this way, he can lay a solid foundation of his further study and reinforce his confidence in learning the language well. For that reason, the teacher, while conveying knowledge, should pay attention to cultivating the learners' sense of themselves and set up new goal at different learning stages----long-term, short-term and medium-term goals, which will help reinforce his long-term motivation. It is when a goal is realized that a new goal is laid down and the motivation is reinforced. This process is the one that short-term motivation is transformed into long-term motivation.

Besides the methods discussed above, there are some other effective strategies to stimulate motivation for learning English, such as creating a comfortable atmosphere, building students' confidence, promoting cooperative learning, and incorporating the multiple intelligences concept in the classroom. All these strategies do have practical application in classroom and can motivate students' interest in English learning, particularly with regard to their consistently weak oral skills.

\section{Strategy in Postgraduates' English acquisition}

\subsection{Two kinds of definition}

The research of learning strategies is an important part of second language acquisition research. Learning strategies influence not only the rate of acquisition, but also the ultimate level of achievement (Wen: 4); they are of great importance to illustrate the individual difference in second language acquisition.

Learning strategies are the particular approaches or techniques that learners employ to try to learn a second language. They can be behavioral or mental; they are typically problem-oriented. As an English teacher, I find students' English achievement in the same course is dramatically different from what we expect, although they are taught by the same teacher with the same teaching material under the same learning environment. Many a student are keenly interested in learning English well and work very hard, however, their performance is not satisfactory as expected. What are reasons behind the differences? As mentioned above, there are many learner-factors putting together with the non-learner factors in the outcome of second language achievement, it is difficult to indicate the elements conductive to the outcome. The key factor for learners in the same learning environment can be their learning strategy. It is easy to point out some effective learning methods because there are books available on learning methodology. But it is a daunting task to find 
strategies suitable for individual learner. I would argue that every individual learner should analyze his or her "learner-factors", and search for him/herself an ideal pattern of language learning. Teachers should do an extensive research on learning strategy to help his or her students to adapt to the learning environment in a favorable manner.

\subsection{Classification of learning strategy}

Various classifications on learning strategy are divided by different researchers, among them Wen's classification is the most effective one. Wen divided learning strategy into two categories: management strategies and language learning strategies. Management strategies are not English-learning specific strategies, they are of a higher level, and they can also be used in other activities. Management strategies are a series of actions such as self-planning, goal-setting, self-monitoring and self-evaluation, etc. These strategies can be used in both short-term and long-term study. Language learning strategies are ideas on language learning, which can be further divided into two groups: traditional strategies and non-traditional strategies. According to Wen, traditional strategies emphasize the explicitness and accuracy of language, while non-traditional strategies emphasizing the implicit and communication of language. Wen also suggests that the combination of the two terms be the best strategies in language learning. The combination must be of moderate degree, that is to say, learners can never go to the extreme of balance of the two terms. For instance, in the process of English learning, it is inevitable that the learners may make some mistakes in their oral practice, so they shouldn't remain silent or shy away speaking out before they are certain to speak accurate sentences. Frequently, they may encounter some new words or different grammar structures, but at least they can make an educated guess instead of consulting the dictionary from time to time. However, to ignore the mistakes and counting too much on guessing may hamper the learners to move on and make progress.

Through the definition and classification of learning strategy, we can see that learning strategy plays an important role in enhancing postgraduates' English competence. The choice of different learning strategies may lead to the different achievements. It is of paramount importance to discuss learning strategy in postgraduates' English learning and teaching.

Most of the studies (O'Malley and Chamot 1990; Wenden and Rubin 1987; Oxford and Crookall 1989) found the learners who were particularly taught strategies performed better than those who were not. Good language learners make use of metacognitive knowledge to help them assess the needs, evaluate progress and give directions to their learning.

\subsection{Approaches to strategy training}

All learning strategy reflects underlying metacognitive processes including planning, monitoring, problem-solving, and evaluating.

Planning strategies help learners develop and use forethought. The teacher provides a task and explains clearly the rationale. Students are asked to choose methods of completing the task and the strategies are employed. These include strategies such as setting goals, activating prior knowledge, predicting, organizational planning and self-management.

Monitoring strategies encourage learners to measure how effective they are while working on a particular task. Examples are selective attention, self-questioning, personalizing, taking notes, using imagery, and self-talk. During this process, they pay attention to the strategy they are using and check comprehension.

Problem-solving strategies provide assistance when a learner has difficulty during a task. They include inferencing, substituting, asking questions to clarify, and using resources. Learners are expected to solve the problems by using these strategies. If this can be achieved, learners will become highly motivated, thus, facilitating learning.

Evaluating strategies encourage reflection on how well a learning task went. Examples are verifying predictions, summarizing, checking goals, and evaluating strategy use.

All these strategies help postgraduates become aware of what strategies they are using, whether these strategies do help their learning. By being given opportunities to practice these strategies, they can know which one is suitable and can be transferred to other tasks.

It must be re-emphasized in conclusion that the issue of strategy training in second language acquisition is far from simple, and there are no simple solutions to the questions of how to promote efficient employment of strategies. The aim of strategy training in English learning lies not in the mastery of strategies but in heightening strategy awareness, in enlarging the range of strategies to be selected, and in enhancing the ability to self-monitor and self-regulate in the learning process. Most of important, metacognitive strategies - the core learning strategies, should be paid much more attention to in language teaching.

\section{Conclusion}

Only through recognizing students' learning motivation can teachers take applicable teaching methods and offer appropriate guidance or advice to students' learning strategy. Different strategies may accommodate learning motivation. 
Integral combination of motivation and strategy is a key to successful language learning, while ill-advised use of learning strategy will lead to failure. It is fitting that we can use a metaphor to describe the relationship between motivation, learning strategy and achievement as a conclusion:

If second language acquisition is a car and all the other factors are essential parts or components, the learners' motivation the fuel supplying the staying power and learning strategy will be the steering wheel deciding the direction and destination of the vehicle. Both of them are very important in accounting for individual difference in second language acquisition. Paying attention to them will teachers to map out more effective and ingenious teaching strategies.

\section{References}

Anderson, N.J. (2002). The role of metacognition in second language teaching and learning. From http://www.cal. org/resources/digest_pdfs /0110_Anderson.pdf/survey.

Benson,P. (2005). Teaching and Researching Autonomy in Language Learning. Beijing: Foreign Language Teaching and Research Press.

Cohen, A.D. (2005). Coming to terms with language learner strategies what do strategy experts think about the terminology and where would they direct their research? Working paper No. 12. from http;//crie.org.nz/research paper/Andrew. Cohen/WP12.pdf/survey2007-7.

Ellis, R. (1994). The Study of Second Language Acquisition. London: Oxford University Press.

Oxford, R. (1990). Language Learning Strategies: What every teacher should know. Rowley, Mass: Newbury House.

Oxford, R. \& D. (1989). Crookall. Research on language learning strategies: methods, findings and instructional issues. The Modern Language Journal, 73(iv), 404-419.

Rees-Miller, J. (1993). A critical appraisal of learner training: theoretical bases and teaching implications. TESOL Quarterly 27(4): 679-689.

Richards, J. C. \& C. (2000). Lockhart. Reflective Teaching in Second Language Classrooms. Beijing: Foreign Language Teaching and Research Press.

Wen, Qiufang. (1999). Psychology in English Study. Lecture Handout, Nanjing University.

Table 1. Factors from various aspects influencing the process of second language acquisition

\begin{tabular}{|c|c|c|c|c|}
\hline \multicolumn{2}{|l|}{ non-learner factors } & \multicolumn{2}{|l|}{ learner factors } & \multirow{3}{*}{$\begin{array}{l}\text { outcomes } \\
\text { English achievement }\end{array}$} \\
\hline environmental & institutional & unmodifiable & modifiable & \\
\hline $\begin{array}{l}\text { social } \\
\text { economic } \\
\text { cultural } \\
\text { linguistic } \\
\text { contexts } \\
\text { Family background }\end{array}$ & $\begin{array}{l}\text { school resources } \\
\text { Teaching qualities } \\
\text { Assessment method }\end{array}$ & $\begin{array}{l}\text { intelligence } \\
\text { aptitude } \\
\text { sex } \\
\text { age }\end{array}$ & $\begin{array}{l}\text { learning purposes } \\
\text { beliefs } \\
\text { effort } \\
\text { management strategies } \\
\text { language learning strategies }\end{array}$ & \\
\hline Presage & process $\rightarrow$ & produc & & \\
\hline
\end{tabular}

